\title{
A!
}

This is an electronic reprint of the original article.

This reprint may differ from the original in pagination and typographic detail.

Tynell, Tommi; Giri, A.; Gaskins, J.; Hopkins, P.E.; Mele, P.; Miyazaki, K.; Karppinen, Maarit Efficiently suppressed thermal conductivity in $\mathrm{ZnO}$ thin films via periodic introduction of organic layers

Published in:

JOURNAL OF MATERIALS CHEMISTRY. A

DOI:

10.1039/C4TA02381A

Published: 01/01/2014

Document Version

Peer reviewed version

Please cite the original version:

Tynell, T., Giri, A., Gaskins, J., Hopkins, P. E., Mele, P., Miyazaki, K., \& Karppinen, M. (2014). Efficiently suppressed thermal conductivity in $\mathrm{ZnO}$ thin films via periodic introduction of organic layers. JOURNAL OF MATERIALS CHEMISTRY. A, 2(xx), 12150-12152. https://doi.org/10.1039/C4TA02381A

This material is protected by copyright and other intellectual property rights, and duplication or sale of all or part of any of the repository collections is not permitted, except that material may be duplicated by you for your research use or educational purposes in electronic or print form. You must obtain permission for any other use. Electronic or print copies may not be offered, whether for sale or otherwise to anyone who is not an authorised user. 


\section{COM MUNICATION}

Citethis: DOI: 10.1039/x0xx00000x

Received 00th January 2012,

Accepted 00thJanuary 2012

DOI: $10.1039 / \times 0 \times x 00000 x$

unw.rsc.org'

\section{Efficiently Suppressed Thermal Conductivity in ZnO Thin Films via Periodic Introduction of Organic Layers}

\author{
Tommi Tynell, ${ }^{a}$ Ashutosh Giri, ${ }^{b}$ John Gaskins, ${ }^{b}$ Patrick E. Hopkins, ${ }^{b}$ Paolo Mele,${ }^{c}$ \\ Koji Miyazaki $^{d}$ and Maarit Karppinen ${ }^{a}$
}

\begin{abstract}
A combination of atomic and molecular layer deposition techniques is used to fabricate thin films of hybrid inorganicorganic superlattice structures with periodically repeating single layers of hydroquinone within a $\mathrm{ZnO}$ or $\left(\mathrm{Zn}_{0.98} \mathbf{A l}_{0.02}\right) \mathrm{O}$ framework. A significant reduction of up to one magnitude in the thermal conductivity of the films as evaluated with the time-domain thermoreflectance technique is observed upon introduction of the organic layers, resulting in a greatly improved thermoelectric performance.
\end{abstract}

The need to improve the performance of thermoelectric materials beyond the limits of conventional materials has led to increased attention to various nanostructuring approaches. Among the most straightforward of these approaches is the fabrication of superlattice (SL) structures with periodicity which may hinder the transport of phonons and/or bring about charge confinement effects. Remarkable improvements in a material's thermoelectric figure of merit have been theoretically predicted and experimentally shown for a number of SL structures composed of two types of inorganic nm-scale layers by reducing the lattice thermal conductivity without significantly affecting the transport of electrons/holes. ${ }^{1-4}$ Here we demonstrate that regularly repeating single layers of organic molecules embedded in a thicker inorganic framework may also efficiently reduce the thermal conductivity and thereby enhance the thermoelectric performance.

Atomic layer deposition (ALD) is a chemical thin film deposition method for inorganics that is based on self-limiting reactions between sequentially pulsed precursors. The technique is particularly well suited for the fabrication of superlattices and other multilayered structures due to the self-limiting nature of the surface reactions. Combined with the strongly emerging molecular layer deposition (MLD) technique for organics, it can be used to deposit hybrid thin films consisting of alternating inorganic and organic layers. ${ }^{5-8}$ Here we employ the combined ALD/MLD technique to deposit SL structures of $(\mathrm{Zn}, \mathrm{Al}) \mathrm{O}$ and single layers of hydroquinone (HQ).
The ALD process for $\mathrm{ZnO}$ is very well established, which along with the relative simplicity of the compound and the promising thermoelectric properties achieved with $\mathrm{Al}$ doping makes the Aldoped $\mathrm{ZnO}$ system ideal for investigating the effects of organic layers on thermoelectric performance. ${ }^{10-12}$ Moreover, the relatively high lattice thermal conductivity of $\mathrm{ZnO}$ enables the realization of potentially large gains in thermoelectric performance if it could be reduced. ${ }^{12,13}$ Recently, we successfully fabricated inorganic-organic SL structures of Al-doped ZnO and HQ by the combined ALD/MLD technique and demonstrated that the addition of organic layers into the structure of $\mathrm{Al}$-doped $\mathrm{ZnO}$ does not result in a notable impairment of the Seebeck coefficient and electrical conductivity of the material; the Seebeck coefficient and resistivity values were $60 \mu \mathrm{V} / \mathrm{K}$ and $70 \mathrm{~m} \Omega \mathrm{cm}$, respectively, for a $\left(\mathrm{Zn}_{0.98} \mathrm{Al}_{0.02}\right) \mathrm{O}$ sample with a 49:1 inorganic to organic ratio. ${ }^{14}$ In this communication, we report a significant decrease in thermal conductivity in our ALD/MLD-fabricated ( $\left.\mathrm{Zn}_{0.98} \mathrm{Al}_{0.02}\right) \mathrm{O}: \mathrm{HQ}$ SL structures, which along with the aforementioned electrical transport properties results in a pronounced improvement in the thermoelectric figure of merit of $\mathrm{ZnO}$.

Non-doped and Al-doped $\mathrm{ZnO}$ thin films containing periodically repeating single HQ layers were prepared on sapphire (0001) substrates using a Picosun R-100 ALD reactor. Five different samples were prepared for this study: $\mathrm{ZnO}, \mathrm{ZnO}: \mathrm{HQ}$ (with layer ratios of 99:1 and 49:1 and SL thicknesses of $c a$. 16 and $8 \mathrm{~nm}$, respectively), $\left(\mathrm{Zn}_{0.98} \mathrm{Al}_{0.02}\right) \mathrm{O}$ and $\left(\mathrm{Zn}_{0.98} \mathrm{Al}_{0.02}\right) \mathrm{O}: \mathrm{HQ}$ (with a ratio of 49:1). All the depositions consisted of 605 ALD/MLD cycles, resulting in films approximately $100 \mathrm{~nm}$ thick. A schematic presentation of the periodic layer-structure of our SL thin-film samples is shown in Figure 1, along with Fourier-transform infrared (FTIR) and X-ray reflectivity (XRR) data for representative samples to evidence, respectively, the presence of the targeted organic layers and the SL repetition. A more detailed description of the sample preparation is found in Ref. 14. 

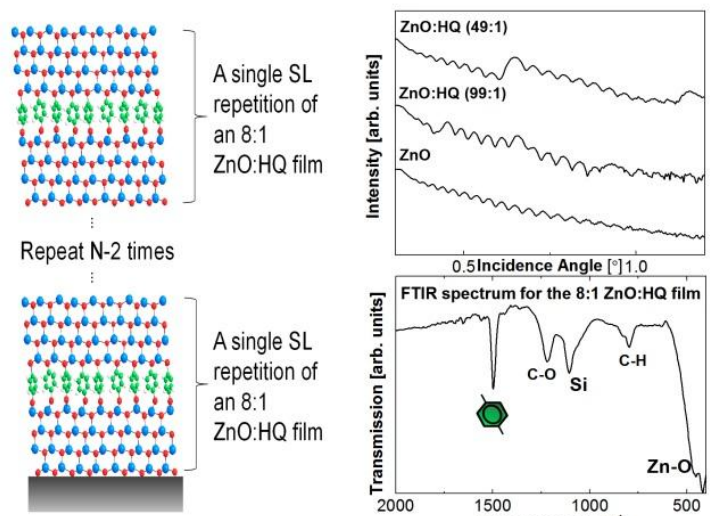

0.5 Incidence Angle $[0] 1.0$

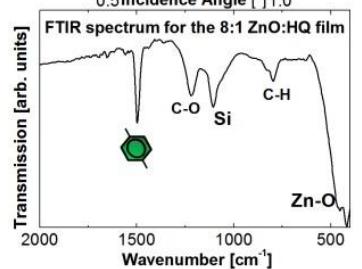

Figure 1. The layered SL structure of the ( $\mathrm{Zn}, \mathrm{Al}) \mathrm{O}: \mathrm{HQ}$ thin films; the XRR and FTIR data are for the ZnO:HQ compositions of 99:1, 49:1 and 8:1 (made for FTIR only), respectively.

The thermal conductivities of the samples were measured at room temperature using the time-domain thermoreflectance (TDTR) technique. TDTR is an optical pump-probe technique used to measure the thermal properties of materials by relating the change in reflectance at the sample surface, and related temperature change, to thermal properties of the underlying layers. ${ }^{15,16}$ The values for the thermal conductivities of the samples, determined by fitting of the TDTR measurement data are presented in Table 1. A more detailed description of the measurement technique and corresponding analyses are given in Refs. 17-20. The calibration data for the thermal conductivity of the $\mathrm{ZnO}$ film was taken from Ref. 21 .

Table 1 . Thermal conductivity values measured for the ( $\mathrm{Zn}, \mathrm{Al}) \mathrm{O}: \mathrm{HQ}$ thin films at room temperature.

\begin{tabular}{|c|c|}
\hline Sample & $\kappa\left(\mathrm{Wm}^{-1} \mathrm{~K}^{-1}\right)$ \\
\hline $\mathrm{ZnO}$ & 43 \\
\hline $\mathrm{ZnO}: \mathrm{HQ}(99: 1)$ & $7.16 \pm 1.44$ \\
\hline $\mathrm{ZnO}: \mathrm{HQ}(49: 1)$ & $4.15 \pm 0.43$ \\
\hline$\left(\mathrm{Zn}_{0.98} \mathrm{Al}_{0.02}\right) \mathrm{O}$ & $6.68 \pm 1.15$ \\
\hline$\left(\mathrm{Zn}_{0.98} \mathrm{Al}_{0.02}\right) \mathrm{O}: \mathrm{HQ}(49: 1)$ & $3.56 \pm 0.27$ \\
\hline
\end{tabular}

The introduction of organic layers into $\mathrm{ZnO}$ causes a significant reduction in the thermal conductivity of the films. Studies on the effects of SL period thickness on thermal conductivity have shown that increasing incoherent boundary scattering by decreasing the period thickness leads to decreased thermal conductivity. ${ }^{21}$ This is consistent with the decrease in thermal conductivity we see between the thicker period (99:1) sample compared to the thinner period (49:1) sample. Aluminum doping also has a reducing effect on the thermal conductivity of $\mathrm{ZnO}$ thin films, as reported in a recent study. ${ }^{22}$ Compared to the $\mathrm{ZnO}: \mathrm{HQ}$ films, the reduction in thermal conductivity from $\mathrm{Al}$ doping is of the same order of magnitude. However, combining both Al doping and introduction of HQ layers resulted in the lowest thermal conductivity value $\left(3.6 \mathrm{Wm}^{-1} \mathrm{~K}^{-1}\right)$ within this study, although the value is only slightly lower than that achieved with HQ layers only.

The observed reductions in the thermal conductivities of the hybrid SL thin-film samples are attributed to the effects of phonon inhibition resulting from the periodic incorporation of HQ layers within the $\mathrm{ZnO}$ structure. The effect is pronounced already at relatively low numbers of HQ layers, i.e. in SL thin films with the 99:1 inorganic-to-organic ratio resulting in HQ layers repeating every $\sim 16 \mathrm{~nm}$ of film thickness; by decreasing the SL thickness down to $\sim 8 \mathrm{~nm}$ for the $49: 1$ films the thermal conductivity was further slightly decreased. These results are in line with a recent report on appreciably low thermal conductivity values achieved for homogeneous hybrid thin films. ${ }^{23}$ Although those films by Liu et $a l .{ }^{23}$ achieved even larger reductions in thermal conductivity than the ones in the present study, they also contained much higher proportions of organic layers. The current results demonstrate that a comparable effect can be obtained with much lower ratios of organic layers, thus influencing film properties such as crystallinity and stiffness to a lesser extent. Indeed, the crystallinity of the ( $\mathrm{Zn}, \mathrm{Al}) \mathrm{O}: \mathrm{HQ}$ films was found to be high and essentially unchanged compared to pure $\mathrm{ZnO} .{ }^{14}$ The reductive effect from $\mathrm{Al}$ doping on the thermal conductivity as confirmed for our samples is well known and is usually attributed to the increased number of phonon scattering sites, which leads to a lower phonon contribution to thermal conductivity. ${ }^{13}$

The reduced thermal conductivity can be particularly useful for thermoelectric applications, where the control of thermal conductivity independent from the Seebeck coefficient and electrical conductivity can greatly improve the performance of a material. We reported the Seebeck coefficients and electrical conductivities of the ( $\mathrm{Zn}, \mathrm{Al}) \mathrm{O}: \mathrm{HQ}$ films in a previous study, and little change was observed in the power factor of the hybrid SL samples compared to $\mathrm{ZnO} .{ }^{14}$ These results were also confirmed for the current films in terms of resistivity values (the sapphire substrate is not ideal for measuring the Seebeck coefficient in our setup). Thus, it would seem that the ten-fold decrease in thermal conductivity observed in the current study would bring about a greatly increased thermoelectric figure of merit for the material. However, care should be taken when drawing conclusions on this point, because while the TDTR technique measures the cross-plane thermal conductivity of the thin films, our existing power factor measurements were made in-plane. ${ }^{14}$ Thus, the values may not be comparable, especially in a highly anisotropic structure such as the current layered ( $\mathrm{Zn}, \mathrm{Al}) \mathrm{O}: \mathrm{HQ}$ thin films. Nonetheless, the observed thermal conductivity values represent a significant reduction and should prove effective in improving the thermoelectric performance of $\mathrm{ZnO}$ thin films.

We foresee that the concept of utilizing organic layers to form a hybrid superlattice structure should be applicable to a range of inorganic materials. The present work provides proof-of-concept for using organic layers to provide a large reduction in thermal conductivity via incoherent boundary scattering. Similar effects should also be achievable with other organic precursors, and indeed, the wealth of available organic molecules that contain suitable functional groups for forming hybrid inorganic-organic superlattices is such that there is virtually no limit to the number of material combinations that can be utilized in these structures.

\section{Acknowledgements}

The present work has received funding from the European Research Council under the European Union's Seventh Framework Programme (FP/2007-2013)/ERC Advanced Grant Agreement (No. 339478), the Aalto Energy Efficiency Research Programme, and the U.S. Army Research Office (W911NF-13-1-0378). PEH is appreciative for support through the U.S. Office of Naval Research Young Investigator Program (N00014-13-4-0528). 


\section{Notes and references}

${ }^{a}$ Department of Chemistry, Aalto University, FI-00076 Aalto, Finland.

${ }^{b}$ Department of Mechanical and Aerospace Engineering, University of Virginia, Charlottesville, 22904 Virginia, USA.

${ }^{c}$ Institute for Sustainable Sciences and Development, Hiroshima University, 739-8530 Higashi-Hiroshima, Japan.

${ }^{d}$ Department of Mechanical and Control Engineering, Kyushu Institute of Technology, 804-8550 Fukuoka, Japan.

1 L. D. Hicks, T. C. Harman, X. Sun and M. S. Dresselhaus, Phys. Rev. $B, 1996, \mathbf{5 3}(16), \mathrm{R} 10493-10496$.

2 G. Chen, Phys. Rev. B, 1998, 57(23), 14958-14973.

3 R. Venkatasubramanian, E. Siivola, T. Colpitts and B. O'Quinn, Nature, 2001, 413, 597-602.

4 J. Carrete, N. Mingo, G. Tian, H. Ågren, A. Baev and P. N. Prasad, J. Phys. Chem. C, 2012, 116, 10881-10886.

5 S. George, A. Dameron, Y. Du, N. M. Adamczyk and S. Davidson, ECS Trans., 2007, 11(7), 81-90.

6 B. H. Lee, M. K. Ryu, S.-Y. Choi, K.-H. Lee, S. Im and M. M. Sung, J. Am. Chem. Soc. 2007, 129, 16034-16041.

7 O. Nilsen, K. B. Klepper, H. Ø. Nielsen and H. Fjellvåg, ECS Trans., 2008, 16(4), 3-14.

8 P. Sundberg and M. Karppinen, Eur. J. Inorg. Chem., 2014, 968-974.

9 B. H. Lee, B. Yoon, V. R. Anderson and S. M. George, J. Phys. Chem. C, 2012, 116, 3250-3257.

10 T. Tynell and M. Karppinen, Semicond. Sci. Technol., 2014, 29, 043001.

11 T. Tynell, H. Yamauchi, M. Karppinen, R. Okazaki and I. Terasaki, J. Vac. Sci. Technol. A, 2013, 31(1), $01 \mathrm{~A} 109$.

12 M. Ohtaki, T. Tsubota, K. Eguchi and H. Arai, J. Appl. Phys., 1996, 79(3), 1816-1818.

13 K. F. Cai, E. Müller, C. Drašar and A. Mrotzek, Mater. Sci. Eng., 2003, B104, 45-48.

14 T. Tynell, I. Terasaki, H. Yamauchi, and M. Karppinen, J. Mater. Chem. A, 2013, 1, 13619-13624.

15 C. A. Paddock and G. L. Eesley, J. Appl. Phys., 1986, 60(1), $285-$ 290.

16 P. E. Hopkins, ISRN Mech. Eng., 2013, 2013, 682586

17 D. G. Cahill, Rev. Sci. Instrum., 2004, 75(12), 5119-5122.

18 A. J. Schmidt, X. Chen and G. Chen, Rev. Sci. Instrum., 2008, 79, 114902.

19 P. E. Hopkins, J. R. Serrano, L. M. Phinney, S. P. Kearney, T. W. Grasser and C. T. Harris, J. Heat Transfer, 2010, 132, 081302.

20 J. Alvarez-Quintana, E. Martínez, E. Pérez-Tijerina, S. A. PérezGarcía and J. Rodríguez-Viejo, J. Appl. Phys., 2010, 107(6), 063713.

21 J. Ravichandran, A. K. Yadav, R. Cheaito, P. B. Rossen, A. Soukiassian, S. J. Suresha, J. C. Duda, B. M. Foley, C. Lee, Y. Zhu, A. W. Lichtenberger, J. E. Moore, D. A. Muller, D. G. Schlom, P. E. Hopkins, A. Majumdar, R. Ramesh and M. A. Zurbuchen, Nature Mater., 2014, 13, 168-172.

22 N. Vogel-Schäuble, T. Jaeger, Y. E. Romanyuk, S. Populoh, C. Mix, G. Jakob and A. Weidenkaff, Phys. Status Solidi RRL, 2013, 7(5), 364-367.

23 J. Liu, B. Yoon, E. Kuhlmann, M. Tian, J. Zhu, S. M. George, Y.-C. Lee, and R. Yang, Nano Lett., 2013, 13, 5594-5599. 